\title{
Transparência e Controle Social nas normas sobre Estudo de Impacto de Vizinhança na Aglomeração Urbana de Piracicaba-SP.
}

\author{
Roberto Braga ${ }^{1}$
}

\begin{abstract}
Resumo: O Estudo de Impacto de Vizinhança - EIV - visa mediar os conflitos de vizinhança resultantes da implantação de empreendimentos com potencial de gerar significativo incômodo ou impacto urbanístico em seu entorno imediato. Trata-se se um importante avanço introduzido pelo Estatuto da Cidade, tanto como instrumento de controle do uso e ocupação do solo, quanto de democratização da gestão urbana local. O EIV, para cumprir as funções previstas no Estatuto da Cidade, deve ter ampla publicidade, ser submetido a audiência pública e ser apreciado por conselho local de política pública. O presente trabalho avalia os Planos Diretores e normas urbanísticas correlatas dos 23 municípios da Aglomeração Urbana de Piracicaba$\mathrm{SP}$, quanto aos aspectos relativos à transparência e o controle social nos Estudos de Impacto de Vizinhança. Os resultados apontaram que nenhum dos municípios analisados adota procedimentos que atendam aos requisitos básicos de transparência pública e de controle social, como previstos na Lei de Acesso à Informação e no Estatuto da Cidade.
\end{abstract}

Palavras-Chave: Estudo de Impacto de Vizinhança, Transparência Pública, Política urbana.

\section{Transparency and Social Control in the legislation of Neighborhood Impact Studies in Urban Agglomeration of Piracicaba-SP.}

\begin{abstract}
The Neighborhood Impact Study (EIV) aims to mediate the neighborhood conflicts resulting from the implementation of projects with potential to generate significant nuisance or urban impact in its immediate surroundings. This is an important advance introduced by the City Statute, both as an instrument to control land use, and of democratization of local urban management. The EIV, in order to fulfill the functions provided for in the City Statute, should be widely publicized, be submitted to a public hearing and be appreciated by a local public policy council. The present study evaluates the Master Plans and related urban norms of the 23 municipalities of the Urban Agglomeration of Piracicaba-SP, regarding the aspects related to transparency and social control in Neighborhood Impact Studies. The results showed that none of the municipalities analyzed adopts procedures that meet the basic requirements of public transparency and social control, as provided for in the Law on Access to Information and in the City Statute.
\end{abstract}

\footnotetext{
${ }^{1}$ Professor Associado de Departamento de Planejamento Territorial e Geoprocessamento da UNESP/Campus de Rio Claro - rbraga@rc.unesp.br.
} 
Keywords: neighborhood impact study; urban policy; public acountability

\section{INTRODUÇÃO}

Os problemas mais recorrentes no processo de desenvolvimento urbano são aqueles ligados aos conflitos de uso do solo. A implantação de obras e empreendimentos geradores de incômodos e impactos urbanísticos afeta a qualidade de vida e a convivialidade nas vizinhanças urbanas, levando a conflitos que o poder público local busca solucionar, nem sempre com sucesso. O Estatuto da Cidade (Lei Federal 10.257/2001), lei máxima da política urbana brasileira, instituiu o Estudo de Impacto de Vizinhança (EIV), visando atenuar tais problemas por meio da análise prévia de empreendimentos potencialmente causadores de incômodo de vizinhança, de modo a que se tomem preventivamente as medidas necessárias à minimização dos conflitos. O EIV, dessa maneira, se torna um instrumento chave na política de controle do uso e da ocupação do solo nas cidades, e de garantia da qualidade de vida.

Outro aspecto importante do EIV é o seu caráter de instrumento de transparência e controle social da política urbana. A exemplo de seu correlato, o Estudo de Impacto Ambiental - EIA, permite não só uma maior transparência quanto ao processo de produção do espaço urbano, mas uma possibilidade de controle social sobre o mesmo. O EIV, se aplicado corretamente, pode ser um fator de diminuição de conflitos urbanísticos, de melhoria da qualidade de vida e de democratização da política urbana.

Os princípios da transparência pública e o controle social são elementos constituintes do estado democrático de direito e devem ser balizas mestres das políticas públicas, como assim determina a Constituição Federal Brasileira. A Política Urbana, conforme estabelece o Estatuto da Cidade, também deve nortear-se por tais princípios, essenciais à consecução da função social da cidade, que é sua base fundamental.

A transparência não só é um dos atributos do EIV, mas um requisito necessário para que o mesmo cumpra seu papel como instrumento de política urbana. Nesse sentido, o presente trabalho tem como objetivo avaliar a adoção do EIV nos Planos Diretores Municipais e legislação correlata dos municípios da Aglomeração Urbana de Piracicaba, no Estado de São Paulo. São avaliados aspectos relativos à publicidade e disponibilização do EIV à consulta da população, à realização de audiências públicas, e à avaliação por órgãos colegiados com participação popular, como os Conselhos da Cidade e os Conselhos Municipais de Meio Ambiente.

\section{TRANSPARÊNCIA E CONTROLE SOCIAL NA POLÍTICA URBANA BRASILEIRA.}

A transparência e o controle social são dois princípios básicos da administração pública democrática. A transparência pública pode ser entendida como um atributo da gestão pública no sentido de proporcionar a qualquer cidadão o acesso a informações e dados públicos necessários à avaliação e ao controle dos 
atos administrativos, geralmente através dos meios de comunicação social, como jornais e sítios de internet. A transparência pública no Brasil é reconhecida pela Constituição Federal como um direito fundamental do cidadão:

[...] todos têm direito a receber dos órgãos públicos informações de seu interesse particular, ou de interesse coletivo ou geral, que serão prestadas no prazo da lei, sob pena de responsabilidade, ressalvadas aquelas cujo sigilo seja imprescindível à segurança da sociedade e do Estado. (Brasil, 1988, Artigo 5, Inciso XXXIII)

A transparência pública, no que se refere à iniciativa, pode ser dividida em dois tipos: ativa e passiva. A transparência ativa consiste na iniciativa do gestor público - voluntária, ou por imposição legal - de dar publicidade a seus atos. A transparência passiva consiste no direto do cidadão e no dever do Estado em dar acesso a documentos públicos (não protegidos por sigilo) a todo cidadão que assim o requeira. (Zucolotto, Teixeira e Riccio, 2015).

A publicidade e a transparência pública são regidas no Brasil pela Lei de Acesso à Informação - LAl (Lei Federal 12.527/2011). Segundo a mesma, a transparência pública deve ser, sobretudo, ativa, ou seja, as informações devem ser divulgadas independentemente da solicitação do cidadão:

É dever dos órgãos e entidades públicas promover, independentemente de requerimentos, a divulgação em local de fácil acesso, no âmbito de suas competências, de informações de interesse coletivo ou geral por eles produzidas ou custodiadas. (Brasil, 2011, Art. $8^{\circ}$ )

Todos os órgãos públicos, de todas as esferas de governo estão submetidos à Lei de Acesso á Informação, que os obriga a desenvolverem canais específicos para atendimento à demanda de informações pelo Cidadão, como os Serviços de Informação ao Cidadão (SIC), no caso da transparência passiva. O poder público é obrigado a responder todas as demandas de informação do Cidadão no prazo hábil não superior a 20 dias, que poderá ser prorrogado por mais 10 dias.

Para o exercício da publicidade ativa, a LAl obriga os órgãos públicos a utilizarem seus sítios oficiais na Internet para a divulgação de informações. Tais sítios deverão atender aos seguintes requisitos mínimos:

I - conter ferramenta de pesquisa de conteúdo que permita o acesso à informação de forma objetiva, transparente, clara e em linguagem de fácil compreensão;

II - possibilitar a gravação de relatórios em diversos formatos eletrônicos, inclusive abertos e não proprietários, tais como planilhas e texto, de modo a facilitar a análise das informações;

III - possibilitar o acesso automatizado por sistemas externos em formatos abertos, estruturados e legíveis por máquina;

IV - divulgar em detalhes os formatos utilizados para estruturação da informação;

V - garantir a autenticidade e a integridade das informações disponíveis para acesso;

VI - manter atualizadas as informações disponíveis para acesso;

VII - indicar local e instruções que permitam ao interessado comunicar-se, por via eletrônica ou telefônica, com o órgão ou entidade detentora do sítio; e 
VIII - adotar as medidas necessárias para garantir a acessibilidade de conteúdo para pessoas com deficiência (Brasil, 2011, Artigo $8^{\circ}, \S^{3} 3^{\circ}$ )

A transparência pública tem como objetivo viabilizar o exercício do controle social do estado. Não há controle social sem transparência. O controle social, na acepção aqui utilizada, consiste na capacidade da sociedade controlar os atos do poder público, em monitorar, fiscalizar e avaliar a gestão pública. O controle social é elemento fundamental do Estado de Direito. Conforme Bitencourt e Pase (2015, p. 294):

Sabe-se que todo controle social requer participação, e que toda participação só é possível em estados que mais do que se intitularem democráticos, recebem e desenvolvem em seu meio pressupostos culturais, sociais, políticos e educacionais que privilegiam a existência de cenários de interlocução das demandas públicas, permitindo uma verdadeira atuação da sociedade sobre ela mesma. Nesse sentido, impossível cindir a conexão entre democracia e controle social, sendo a primeira, uma verdadeira mola propulsora, ou mesmo pressuposto para a existência do controle.

No Estado de Direito há duas formas essenciais de controle da gestão pública: o controle institucional e o controle social. O controle institucional é o controle interno, efetuado pelos Tribunais de Conta, pelas Controladorias e pelo Ministério Público. No entanto, o controle interno não é suficiente para garantir o correto controle da aplicação dos gastos públicos e da condução das políticas públicas. Como bem assinala a CGU (2012), o Controle Social é necessário:

[...] tendo em vista a complexidade das estruturas político-sociais de um país e do próprio fenômeno da corrupção, o controle da Administração Pública não se deve restringir ao controle institucional. É fundamental para toda a coletividade que ocorra a participação dos cidadãos e da sociedade organizada no controle do gasto público, monitorando permanentemente as ações governamentais e exigindo o uso adequado dos recursos arrecadados. A isto se denomina "controle social" (CGU, 2012, p. 16)

O Controle Social pode ser exercido de várias formas, mas podem ser destacados dois instrumentos fundamentais: os Conselhos de Política Pública e as Audiências Públicas.

Os Conselhos de Política Pública são órgãos colegiados permanentes com participação, geralmente paritária, de representantes governamentais e da sociedade civil. Atuam na fiscalização, na formulação e na condução de políticas públicas, e são o principal dispositivo de participação cidadã e Controle Social:

O Conselho é um instrumento para a concretização do controle social - uma modalidade de exercício do direito à participação política, que deve interferir efetivamente no processo decisório dos atos governamentais e também durante a sua execução. A importância dos conselhos está no seu papel de fortalecer a participação democrática da população na formulação e implementação de políticas públicas. Os conselhos são o principal canal de participação popular encontrado nas três instâncias de governo (federal estadual e municipal). (ENAP, 2015) 
O Estatuto da Cidade prevê a existência de órgãos colegiados de política urbana nos níveis Federal, Estadual e Municipal. Em nível Federal, existe o Conselho das Cidades (ConCidades), que é o órgão participativo máximo da política urbana no Brasil. É um colegiado com caráter consultivo e deliberativo e faz parte da estrutura do Ministério das Cidades. Em nível municipal, existem os Conselhos da Cidade locais, colegiados criados por Lei Municipal, dos quais participam agentes públicos e representantes de entidades da sociedade civil. Os mesmos atuam como órgãos consultivos e deliberativos na condução da política urbana local, sobretudo no processo de elaboração, implementação e revisão do Pleno Diretor e demais instrumentos urbanísticos previstos no Estatuto da Cidade, o que inclui também o Estudo de Impacto de Vizinhança.

As Audiências Públicas são reuniões entre agentes do governo e cidadãos para discutir e propor diretrizes para elaboração de leis, projetos, planos e implantação de obras, ou empreendimentos de interesse público. As audiências são realizadas pelo órgão público competente, por iniciativa própria ou por solicitação de entidades da sociedade civil.

As audiências públicas estão previstas no Estatuto da Cidade e são obrigatórias no processo de elaboração, revisão e execução do Plano Diretor e demais instrumentos de política urbana. Nesse caso, as audiências públicas devem ser realizadas tanto no âmbito do poder executivo, no momento de elaboração dos planos, projetos e leis, quanto no âmbito do poder legislativo, no momento da aprovação das leis.

Para que atinjam o seu objetivo de democratização e controle social, as mesmas devem ser dotadas de máxima transparência e publicidade. Os participantes devem ter acesso amplo e prévio a toda a documentação referente à audiência pública, sobretudo por meio da página oficial da prefeitura na Internet, cujo uso se tornou obrigatório pela Lei de Acesso à Informação. A audiência pública deve ser amplamente divulgada e com antecedência suficiente para a organização dos cidadãos interessados utilizando-se, para isso, os meios de comunicação social disponíveis, como jornais e a própria página oficial da Prefeitura na Internet.

A transparência e o controle social também são fundamentos da política urbana no Brasil. Segundo o Estatuto da Cidade, a gestão democrática da cidade é uma diretriz da política urbana brasileira. Conforme essa mesma lei, a gestão democrática deve se dar por meio da participação popular, que se consubstancia por meio da participação direta da população e de suas entidades representativas. Nesse sentido, essa lei Federal prevê os seguintes instrumentos:

I - órgãos colegiados de política urbana, nos níveis nacional, estadual e municipal;

II - debates, audiências e consultas públicas;

III - conferências sobre assuntos de interesse urbano, nos níveis nacional, estadual e municipal;

IV - iniciativa popular de projeto de lei e de planos, programas e projetos de desenvolvimento urbano; (Brasil, 2001, Art. 43)

O Estatuto da Cidade determina que o poder público garanta, na elaboração e na implementação do Plano Diretor (o que se estende a seus instrumentos derivados), os seguintes meios de transparência e controle social: 
I - a promoção de audiências públicas e debates com a participação da população e de associações representativas dos vários segmentos da comunidade;

II - a publicidade quanto aos documentos e informações produzidos;

III - o acesso de qualquer interessado aos documentos e informações produzidos (Brasil, 2001, artigo 40).

Percebe-se que a legislação garante tanto a publicidade passiva quanto a ativa na condução da política urbana. Vale salientar que o Estatuto da Cidade determina (em seu Artigo 52) que o Prefeito Municipal incorre em crime de improbidade administrativa quando deixa de garantir o cumprimento do processo participativo na política urbana.

A transparência e o Controle Social são pressupostos da Política Urbana. A publicidade dos atos públicos e a disponibilização de documentos e informações sobre a formulação da política urbana e a aplicação de seus instrumentos, devem ser feitos de modo ativo, por iniciativa do gestor público, sem a obrigatória necessidade de requerimento. Normas, planos, estudos e relatórios relativos à política urbana devem ser disponibilizados na página oficial da prefeitura na internet para acesso e controle de qualquer cidadão. A elaboração, revisão e a aplicação dos instrumentos urbanísticos previstos no Estatuto da Cidade devem ser objeto de ampla publicidade e de consulta a órgãos colegiados participativos, bem como submetida a audiências e consultas públicas.

\section{O ESTUDO DE IMPACTO DE VIZINHANÇA COMO INSTRUMENTO DE TRANSPARÊNCIA E CONTROLE SOCIAL DA POLÍTICA URBANA}

O estudo prévio de impacto de vizinhança (EIV) é um instrumento de transparência e participação adotado no ordenamento urbanístico brasileiro pelo Estatuto da Cidade. Essa lei faculta aos municípios a exigência de tal estudo para a obtenção de licenças de construção ou funcionamento de empreendimentos potencialmente causadores de incômodo ou impacto urbanístico significativo ao seu entorno. Esse instrumento visa prevenir e minimizar conflitos de uso do solo, antecipando-se a potenciais situações de inadequação entre usos e atividades em uma mesma vizinhança.

Além de sua característica de instrumento de controle do uso e ocupação do solo urbano, o EIV permite aos moradores de uma vizinhança não só uma maior transparência do processo de urbanização, mas a possibilidade de participação na gestão de seu território. O EIV é tanto um instrumento de promoção do desenvolvimento urbano sustentável, quanto um instrumento de participação e democratização da gestão urbana. Como bem assinala Rocco (2009, p. 24):

Esse importante mecanismo preventivo de controle social sobre o desenvolvimento local é instrumento da Política Urbana Nacional. Possui papel de publicizar informações, até então ocultas e inacessíveis ao conhecimento da população, sobre determinados empreendimentos a serem instalados em zonas urbanas de convício público. 
Da mesma maneira, Rolnik et. al. (2001, p. 199) assinalam que o objetivo do EIV é "democratizar o sistema de tomada de decisões sobre os grandes empreendimentos a serem realizados na cidade, dando voz aos bairros e comunidades que estejam expostos aos impactos".

Nesse sentido, o EIV possui alguma similaridade com o Estudo de Impacto Ambiental (EIA), mas não o substitui, pois se limita a questões e aspectos específicos do ambiente construído, na escala urbana das unidades de vizinhança (bairros). O mesmo deve abordar os impactos do empreendimento em aspectos urbanísticos, tais como: adensamento populacional; capacidade dos equipamentos urbanos e comunitários; alterações no uso e ocupação do solo; valorização imobiliária; geração de tráfego, e demanda por transporte público; alterações na ventilação e iluminação dos imóveis adjacentes; e alterações na paisagem urbana e nos patrimônios natural e cultural (Brasil, 2001).

A adoção do EIV deve ser regulamentada no Plano Diretor e em legislação municipal específica que definirá normas e parâmetros necessários para a aplicação desse instrumento.

O Estatuto da Cidade não especifica os tipos de empreendimento que estão sujeitos à exigência de EIV, deixando a cargo da legislação municipal tal definição. O EIV deve avaliar os efeitos positivos e negativos do empreendimento à população vizinha ao mesmo, contemplando minimamente as seguintes questões:

I - adensamento populacional;

II - equipamentos urbanos e comunitários;

III - uso e ocupação do solo;

IV - valorização imobiliária;

$\mathrm{V}$ - geração de tráfego e demanda por transporte público;

VI - ventilação e iluminação;

VII - paisagem urbana e patrimônio natural e cultural. (Brasil, 2001, Artigo 37)

A publicidade no EIV deve ser ativa, por demanda do cidadão interessado - o Estatuto da Cidade é taxativo quanto à necessidade de realização de audiências públicas no seu processo de aprovação, ao exigir:

[...] audiência do Poder Público municipal e da população interessada nos processos de implantação de empreendimentos ou atividades com efeitos potencialmente negativos sobre o meio ambiente natural ou construído, 0 conforto ou a segurança da população. (Brasil, 2001, Artigo $2^{\circ}$, inciso XIII)

Não existe uma norma geral, nacional, para os processos de elaboração, análise e aprovação do EIV. Cada município, atendendo às diretrizes estabelecidas no Estatuto da Cidade deverá, caso adote este instrumento, estabelecer as suas regras, que podem estar fixadas totalmente no Plano diretor, na Lei de uso e ocupação do solo, ou em legislação específica. No entanto, é necessário que a adoção do EIV no licenciamento urbanístico municipal esteja prevista no Plano Diretor, como qualquer outro instrumento do Estatuto da Cidade.

A exemplo do Estudo de Impacto Ambiental, seu correlato mais próximo, o EIV deve ser elaborado por equipe multidisciplinar, a expensas do empreendedor, geralmente com base em um termo de referência fornecido pelo poder público. Após sua elaboração, o EIV é encaminhado ao órgão público, o qual deverá dar publicidade ao mesmo. Essa publicidade pode ocorrer de três maneiras: por informe 
no Diário Oficial sobre a apresentação do EIV; por informe na página eletrônica da Prefeitura na Internet, e por informe em jornal de grande circulação.

O EIV também deverá ser disponibilizado para consulta pública por qualquer cidadão interessado, fisicamente no órgão público responsável, ou em meio digital na página da Prefeitura, na Internet. Assim como ocorre no processo de análise de EIA/RIMA (Estudo de Impacto Ambiental/Relatório de Impacto Ambiental), é importante que seja estabelecido um prazo hábil para consulta e contestação do mesmo, por parte dos cidadãos interessados.

No âmbito do órgão municipal regulador, o EIV é geralmente avaliado por uma comissão ou grupo de análise multidisciplinar constituído por membros de várias secretarias ou departamentos da Prefeitura Municipal. A esse grupo cabe analisar o EIV e emitir parecer técnico quanto aos impactos ou incômodos a serem gerados, bem como das medidas mitigatórias ou compensatórias propostas pelo empreendedor. De modo a cumprir o princípio da gestão participativa e do controle social previstos no Estatuto da Cidade e na Lei de Acesso à Informação, o EIV e o parecer técnico devem ser submetidos à apreciação dos órgãos colegiados locais ligados à política urbana e à política ambiental, ao conselho da Cidade e ao Conselho de Meio Ambiente.

Após o parecer técnico, a publicação, e a disponibilização do EIV para consulta da população afetada, podem ser realizadas audiências públicas por iniciativa do próprio órgão licenciador - caso constate significativo impacto do empreendimento -, ou por solicitação de qualquer morador da área afetada.

A realização de audiência pública para discussão de EIV deve ser regulamentada em legislação municipal. Recomenda-se que haja franca publicidade e que a mesma seja marcada com antecedência suficiente para que os interessados possam examinar a documentação. No processo de licenciamento ambiental federal, as audiências públicas são marcadas com ampla divulgação e com antecedência mínima de 45 dias (IBAMA, 20012). No município de São Paulo-SP, a convocação de audiência pública é realizada com a antecedência mínima de 20 dias, e a publicidade da mesma é feita no diário oficial do município, na página oficial da prefeitura na internet, bem como em jornal de grande circulação, a expensas do empreendedor.

Outro aspecto importante a ser regulamentado nas audiências públicas é seu horário de realização que deve ser compatível com a presença de moradores trabalhadores, ou seja, fora de horário comercial. É importante também a disponibilização de toda a documentação pertinente (tanto o EIV, quanto o parecer técnico do órgão regulador) em meio digital na internet, como é usualmente feito no caso do EIA/RIMA.

Para que o EIV cumpra adequadamente sua função, contribuindo para a sustentabilidade e a gestão democrática da cidade, deve haver transparência e abertura de canais de controle social em seu processo de análise e aprovação. Como mencionado anteriormente, isso implica na necessidade de divulgação ampla nos meios de comunicação, bem como a realização de audiências públicas e análise por parte de órgãos colegiados participativos, como o Conselho da Cidade local ou mesmo o Conselho Municipal de Meio Ambiente. 


\section{ESTUDO DE CASO}

A Aglomeração Urbana de Piracicaba - AUP (figuras 1 e 2) faz parte da Macrometrópole Paulista, um aglomerado urbano que abriga as Regiões Metropolitanas da Grande São Paulo, de Campinas e da Baixada Santista, além das Aglomerações Urbanas de Sorocaba e Piracicaba e da Unidade Regional de Bragança Paulista. Ao todo são 174 municípios com uma população total de 45 milhões de habitantes.

Figura 1 - Localização da Aglomeração Urbana de Piracicaba.

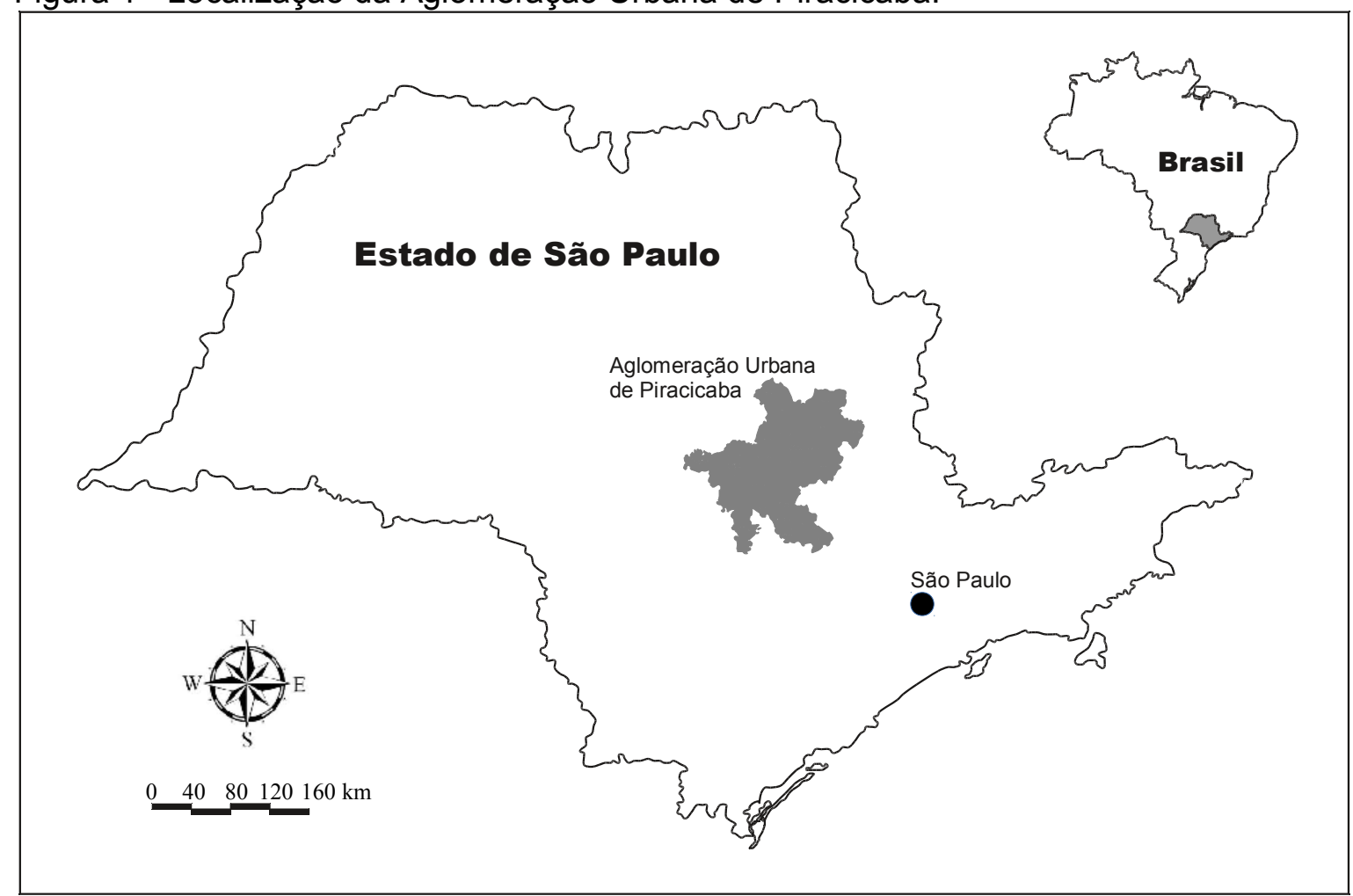

Fonte: Elaborado pelo Autor 
Figura 2 - Municípios da Aglomeração Urbana de Piracicaba.

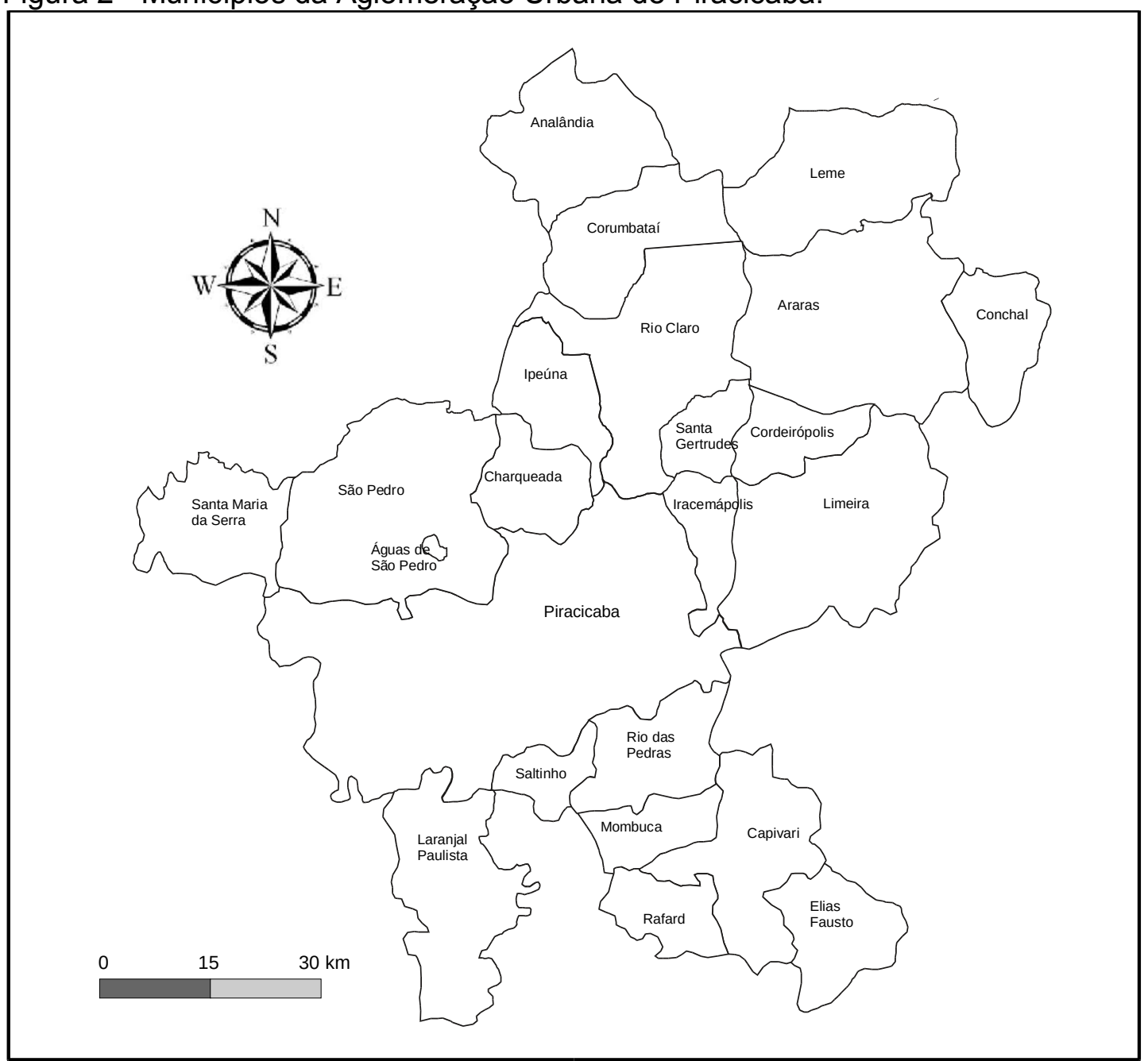

Fonte: Elaborado pelo autor

A AUP é composta por 23 municípios que abrigam uma população de 1,46 milhões de habitantes (Quadro 1). A região apresenta 13 municípios com mais de 20 mil habitantes, que por lei são obrigados a elaborar o Plano Diretor. Destes, cinco possuem população acima de 100 mil habitantes, sendo o mais populoso Piracicaba, com 397 mil habitantes.

Dos 23 municípios da AUP, menos de 50\% (11 municípios) adotam o EIV: Piracicaba, Limeira, Rio Claro, Araras, São Pedro, Rio das Pedras, Conchal, Cordeirópolis, Iracemápolis, Santa Maria da Serra e Analândia (Quadro 1).

Quadro 1 - Municípios da AUP- População, adoção de EIV e procedimentos de transparência e controle público

\begin{tabular}{|l|r|r|}
\hline \multicolumn{1}{|c|}{ Município } & População $-2017^{*}$ & Adota EIV \\
\hline Piracicaba & 397.322 & Sim \\
\hline Limeira & 300.911 & Sim \\
\hline Rio Claro & 202.952 & Sim \\
\hline Araras & 131.282 & Sim \\
\hline Leme & 101.184 & Não \\
\hline Capivari & 54.298 & Não \\
\hline São Pedro & 34.898 & Sim \\
\hline
\end{tabular}




\begin{tabular}{|l|r|r|}
\hline Rio das Pedras & 33.935 & Sim \\
\hline Laranjal Paulista & 27.890 & Não \\
\hline Conchal & 27.554 & Sim \\
\hline Santa Gertrudes & 25.637 & Não \\
\hline Cordeirópolis & 23.793 & Sim \\
\hline Iracemápolis & 23.264 & Sim \\
\hline Elias Fausto & 17.393 & Não \\
\hline Charqueada & 16.772 & Não \\
\hline Rafard & 9.054 & Não \\
\hline Saltinho & 8.019 & Não \\
\hline Ipeúna & 7.177 & Não \\
\hline Sta. Maria da Serra & 6.021 & Sim \\
\hline Analândia & 4.845 & Sim \\
\hline Corumbataí & 4.054 & Não \\
\hline Mombuca & 3.470 & Não \\
\hline Águas de São Pedro & 3.268 & Não \\
\hline TOTAL & 1.464 .993 & --- \\
\hline
\end{tabular}

* Fonte: Fundação SEADE / NSA = Não se Aplica / Elaborado pelo Autor

Considerando os onze municípios que adotaram o EIV, pode-se perceber (Quadro 2) que nenhum dos mesmos adota todos os procedimentos necessários à garantia de transparência e controle social nos Estudos de Impacto de Vizinhança. Apenas um município, Cordeirópolis (de apenas 23 mil habitantes), prevê os três procedimentos básicos: Publicidade, Audiência Pública e consulta a Conselho de Política Pública. Ainda assim a publicidade é colocada apenas de maneira genérica, sem previsão de publicação em jornal ou na página da prefeitura na internet.

Piracicaba, o município cabeça da AUP, determina genericamente a necessidade de publicidade, mas não prevê a disponibilização do EIV na prefeitura para consulta pública. A realização de audiências públicas é prevista somente quando solicitado por interessados, e não há a previsão de análise do processo por Conselho de Política Pública. 


\section{Quadro 2 - Aglomeração urbana de Piracicaba - Municípios que adotam o EIV - Procedimentos de Transparência e}

\section{Controle Social}

\begin{tabular}{|c|c|c|c|c|c|c|c|c|c|c|c|}
\hline Procedimento & Piracicaba & Limeira & Rio Claro & Araras & $\begin{array}{l}\text { São } \\
\text { Pedro }\end{array}$ & $\begin{array}{l}\text { Rio das } \\
\text { Pedras }\end{array}$ & Conchal & $\begin{array}{l}\text { Cordei- } \\
\text { rópolis }\end{array}$ & $\begin{array}{l}\text { Iracemá- } \\
\text { polis }\end{array}$ & $\begin{array}{c}\text { Santa Maria } \\
\text { da Serra }\end{array}$ & $\begin{array}{l}\text { Analân- } \\
\text { dia }\end{array}$ \\
\hline Publicidade do EIV/RIV & Sim & --- & Sim & Sim & Sim & ---- & Sim & Sim & --- & --- & --- \\
\hline $\begin{array}{l}\text { Determina a publicidade } \\
\text { do EIV em jornais }\end{array}$ & --- & --- & --- & --- & --- & --- & --- & --- & --- & --- & --- \\
\hline $\begin{array}{l}\text { Determina a publicidade } \\
\text { do EIV na página da } \\
\text { prefeitura na Internet }\end{array}$ & --- & --- & --- & --- & --- & --- & --- & --- & --- & --- & --- \\
\hline $\begin{array}{l}\text { Determina a } \\
\text { disponibilização do } \\
\text { EIR/RIV para consulta } \\
\text { física na Prefeitura }\end{array}$ & --- & --- & Sim & Sim & Sim & --- & Sim & Sim & --- & --- & --- \\
\hline $\begin{array}{l}\text { Determina a } \\
\text { disponibilização do } \\
\text { EIV/RIV para consulta } \\
\text { digital na internet. }\end{array}$ & --- & --- & --- & --- & --- & --- & --- & --- & --- & --- & --- \\
\hline $\begin{array}{l}\text { Especifica prazo para } \\
\text { consulta pública ao EIV }\end{array}$ & --- & --- & Sim* & --- & --- & --- & --- & --- & --- & --- & --- \\
\hline $\begin{array}{l}\text { Publicação do resultado } \\
\text { da análise do EIV/RIV }\end{array}$ & --- & --- & Sim & --- & --- & --- & --- & -- & --- & --- & -- \\
\hline $\begin{array}{l}\text { Previsão de realização } \\
\text { de Audiência pública }\end{array}$ & $\mathrm{Sim}^{1}$ & --- & --- & $\mathrm{Sim}^{1}$ & --- & --- & --- & $\mathrm{Sim}^{1}$ & --- & --- & --- \\
\hline $\begin{array}{l}\text { Estabelece regras para } \\
\text { a realização da } \\
\text { audiência pública }\end{array}$ & --- & --- & --- & --- & --- & --- & --- & --- & --- & --- & --- \\
\hline $\begin{array}{l}\text { Análise por órgão } \\
\text { colegiado com } \\
\text { participação popular }\end{array}$ & ב--- & "--- & ב--- & --- & ב-- & $\mathrm{SSim}^{2}$ & ב--- & $\operatorname{Sim}^{2,3}$ & $\mathrm{SSim}^{2}$ & ב--- & ב--- \\
\hline
\end{tabular}

* pelo prazo de 15 dias / 1- apenas quando solicitado por morador da área atingida / 2- em caráter apenas consultivo /

3 - apenas para empreendimentos executados pelo poder público municipal. Elaborado pelo Autor. 
Rio Claro foi o município que melhor atendeu ao quesito transparência com a determinação de publicidade, de disponibilização do EIV para consulta na prefeitura, de prazo para análise, e de publicação do parecer técnico sobre o EIV. No entanto, a legislação desse município não prevê qualquer instrumento de controle social - seja audiência pública, ou análise por conselho de política pública -, o que faz com que os procedimentos de transparência percam o objetivo do controle social.

De maneira geral, nenhum dos municípios cumpre as determinações do Estatuto da Cidade ou da Lei de Acesso à Informação quanto à publicidade e ao controle social no EIV. Nenhum dos municípios determina a publicação em jornal de grande circulação, a publicidade, ou mesmo a disponibilização do EIV para consulta na página da prefeitura na Internet. Nenhum dos municípios determina a realização de audiência pública por iniciativa do poder público, mas apenas por solicitação de cidadãos interessados.

\section{CONCLUSÕES}

Ao incluir o Estudo de Impacto de Vizinhança no rol dos instrumentos de política urbana, o Estatuto da Cidade deu um passo importante nos rumos do desenvolvimento urbano sustentável e da gestão democrática da cidade. No entanto, a observação dos resultados da avaliação da aplicação do EIV nos Planos Diretores dos municípios da Aglomeração Urbana de Piracicaba indica que sua implantação tem se dado de maneira inadequada, resultando em baixa efetividade no cumprimento de seus objetivos.

Dos 23 municípios da AUP, apenas 11 adotam o EIV, dos quais seis adotam algum procedimento de transparência pública. Cinco municípios adotam algum procedimento de controle social. Nos critérios Transparência e Controle Social são três municípios, e nos procedimentos Publicidade, Audiência Pública e análise por Conselho de Política Pública, figura apenas o município de Cordeirópolis. O quadro se revela ainda mais grave quando se observa que nenhum dos municípios determina a publicidade do EIV em jornal, ou na página da prefeitura na Internet.

Nesse sentido, a simples menção genérica à necessidade de publicidade do EIV não é suficiente para a garantia da transparência. É necessária a efetivação da publicidade através dos meios de comunicação social e do uso das tecnologias de informação via internet, o que não está contemplado nas normas urbanísticas dos municípios analisados. Essa omissão compromete a possibilidade de controle social no processo de análise dos EIV.

Reiteramos que o exercício do controle social no processo de aprovação dos EIV deve ser garantido por meio de seus dois instrumentos principais: a audiência pública e a análise por conselho de política pública. A exemplo do EIA/RIMA, a iniciativa para as Audiências, deve partir também do poder público. Do mesmo modo, o EIV deve ser submetido à apreciação por colegiados locais de política pública, como o Conselho da Cidade e o Conselho Municipal de Meio Ambiente.

Desta forma, a partir da análise dos Planos Diretores e da legislação urbanística dos municípios da Aglomeração Urbana de Piracicaba, conclui-se que a aplicação do Estudo de Impacto de Vizinhança não atende aos requisitos mínimos de transparência pública e de controle social. Assim sendo, corrobora-se a hipótese de que esse importante instrumento de controle do uso do solo não deve estar cumprindo os objetivos de promover o desenvolvimento urbano sustentável e a gestão democrática da cidade, conforme determina o Estatuto da Cidade. 


\section{BIBLIOGRAFIA}

ASSUNÇÃO, Linara Oeiras. A Participação Popular nas Audiências Públicas para Licenciamento Ambiental. Revista Científica do Curso de Direito do CEAP, v.1, n.1, 2011.

BITENCOURT, C. M.; PASE, E. S. A necessária relação entre democracia e controle social: discutindo os possíveis reflexos de uma democracia "não amadurecida" na efetivação do controle social da Administração Pública. Revista de Investigações Constitucionais, vol. 2 | n. 1 | janeiro/abril 2015.

BRASIL. Constituição da República Federativa do Brasil de 1988. Brasília, DF, 2018

BRASIL. Estatuto da Cidade. Lei $n^{\circ} 10.257$, de 10 de julho de 2001. Brasília, DF, 2001

CGU - Controladoria Geral da União. Controle Social: Orientação aos Cidadãos para participação na gestão pública e exercício do Controle Social. Brasília: CGU, 2012.

ENAP - Escola Nacional de Administração Pública. Controle Social - Módulo 3: Controle Social e Cidadania I. Brasília: ENAP, 2015.

ENAP - Escola Nacional de Administração Pública. Acesso à Informação - Módulo 1: o direito de acesso à informação no Brasil: contexto, conceitos, abrangência e operacionalização. Brasília: ENAP, 2018.

FIGUEIREDO, V. da S.; SANTOS, W. J. L. dos. Transparência e Controle Social na Administração Pública. Temas de Administração Pública, v 8, n.1, 2013.

JOHN, Natacha Souza; ODORISSI, Fernanda Favarini. O Licenciamento Ambiental e o Princípio da Publicidade: Um Instrumento de Efetividade na Participação Pública. Revista do CAAP-Belo Horizonte, n. 1, v. XVIII, 2012

GOULART, Jefferson Oliveira; TERCI, Eliana Tadeu; OTERO, Estevam Vanale. Participação política e gestão urbana sob o Estatuto da Cidade. Revista Brasileira de Gestão Urbana, 2015 jan./abr., 7(1), 122-135.

IBAMA - Instituto Brasileiro do Meio Ambiente e dos Recursos Naturais Renováveis. Guia de Procedimentos do Licenciamento Ambiental Federal. Brasília: IBAMA, 2002.

OLIVEIRA, Jorge Falcão Marques de; LOMBA, Juliana Ferretti. Estudo prévio de impacto de vizinhança e função social da propriedade urbana: problematização e análise jurisprudencial do Tribunal de Justiça do estado de São Paulo. Revista Digital de Direito Administrativo- RDDA, v. 2, n.2, 2015.

ROCCO, Rogério. Estudo de impacto de vizinhança: instrumento de garantia do direito às cidades sustentáveis. Ed. Lumen Juris: Rio de Janeiro, 2009. 
ROLNIK, Raquel et. al. Estatuto da Cidade: guia para implementação pelos municípios. Brasília: Câmara dos Deputados, 2001.

VIEIRA, A. B. Estudo de Impacto de Vizinhança. Revista Direito Ambiental e Sociedade, v. 2, n. 1, 2012. 